\title{
Avaliação de forças resultantes de contato oclusal prematuro entre primeiros molares: Um estudo 3D de elementos finitos
}

\author{
Evaluation of Forces Resulting from Premature Occlusal Contact Between First Molars: A 3D \\ Finite Element Study
}

Evaluación de las fuerzas resultantes del contacto oclusal prematuro entre los primeros molares: un estudio de elementos finitos en 3D

Recebido: 02/11/2021 | Revisado: 10/11/2021 | Aceito: 14/11/2021 | Publicado: 24/11/2021

\author{
Daisilene Baena Castillo \\ ORCID: https://orcid.org/0000-0003-4261-7503 \\ Universidade Federal de Mato Grosso do Sul, Brasil \\ E-mail: daisilene@hotmail.com \\ Victor Augusto Alves Bento \\ ORCID: https://orcid.org/0000-0003-0558-4239 \\ Universidade Estadual Paulista “Júlio de Mesquita Filho”, Brasil \\ E-mail: vtrbento97@gmail.com \\ Jànes Landre Júnior \\ ORCID: https://orcid.org/0000-0001-6640-3601 \\ Pontifícia Universidade Católica de Minas Gerais, Brasil \\ E-mail: mostraipuc@pucminas.br \\ Paulo Isaías Seraidarian \\ ORCID: https://orcid.org/0000-0003-4274-7340 \\ Pontifícia Universidade Católica de Minas Gerais, Brasil \\ E-mail: seraidarian@gmail.com
}

\begin{abstract}
Resumo
Os contatos oclusais são considerados fatores importantes a serem considerados diante do tratamento odontológico, pois contatos prematuros oclusais podem implicar em danos potenciais a saúde bucal. Os eventos biomecânicos que resultam de contatos prematuros oclusais sobre os dentes e seus tecidos de suporte, ainda não estão esclarecidos. Assim, o propósito deste estudo foi avaliar, por meio do método de elementos finitos tridimensional, a distribuição das tensões, nos dentes e tecidos de sustentação, geradas por diferentes contatos prematuros em primeiro molar superior e inferior. A pesquisa foi delineada considerando dois fatores de contatos prematuros possíveis de ocorrer clinicamente, contato "A" e contato "B". Foi gerado malhas através do software Solidworks ${ }^{\circledR}$ e os testes foram realizados pelo software de elementos finitos Cosmos Design Star, com intensidade da carga de $100 \mathrm{~N}$ na face oclusal. Mapas de von Mises foram gerados para análise de distribuição de tensão. Maiores tensões foram geradas pelo contato prematuro "A". Os pontos de contato prematuro em primeiros molares geraram grandes concentração de tensões nas cúspides cêntricas, sendo que nos primeiros molares superiores, dependendo do tipo de contato, as tensões podem se dissipar para o ápice da raíz. As tensões são melhor dissipadas no tecido de sustentação do hemi-arco superior.
\end{abstract}

Palavras-chave: Oclusão dentária; Sistema estomatognático; Análise de elementos finitos.

\begin{abstract}
Occlusal contacts are considered important factors to be considered before dental treatment, as premature occlusal contacts can cause potential damage to oral health. The biomechanical events that result from premature occlusal contacts on teeth and their supporting tissues remain unclear. Thus, the purpose of this study was to evaluate, using the three-dimensional finite element method, the distribution of stresses, in teeth and supporting tissues, generated by different premature contacts in upper and lower first molars. The research was designed considering two factors of premature contacts that are possible to occur clinically, " $\mathrm{A}$ " contact and "B" contact. Meshes were generated using the Solidworks ${ }^{\circledR}$ software and the tests were performed using the Cosmos Design Star finite element software, with a load intensity of $100 \mathrm{~N}$ on the occlusal face. Von Mises maps were generated for stress distribution analysis. Higher stresses were generated by premature "A" contact. Premature contact points in first molars generated large concentrations of stresses in the centric cusps, and in the upper first molars, depending on the type of contact, the stresses can dissipate towards the apex of the root. Stresses are better dissipated in the support fabric of the upper hemi-arch.
\end{abstract}

Keywords: Dental occlusion; Stomatognathic system; Finite element analysis. 


\begin{abstract}
Resumen
Los contactos oclusales se consideran factores importantes a considerar antes del tratamiento dental, ya que los contactos oclusales prematuros pueden causar daños potenciales a la salud bucal. Los eventos biomecánicos que resultan de contactos oclusales prematuros en los dientes y sus tejidos de soporte siguen sin estar claros. Así, el propósito de este estudio fue evaluar, utilizando el método de elementos finitos tridimensionales, la distribución de tensiones, en dientes y tejidos de soporte, generadas por diferentes contactos prematuros en primeros molares superiores e inferiores. La investigación se diseñó considerando dos factores de contactos prematuros que pueden ocurrir clínicamente, el contacto "A" y el contacto "B". Las mallas se generaron con el software Solidworks® y las pruebas se realizaron con el software de elementos finitos Cosmos Design Star, con una intensidad de carga de $100 \mathrm{~N}$ en la cara oclusal. Se generaron mapas de Von Mises para el análisis de distribución de tensiones. Se generaron tensiones más altas por contacto "A" prematuro. Los puntos de contacto prematuros en los primeros molares generan grandes concentraciones de tensiones en las cúspides céntricas, y en los primeros molares superiores, según el tipo de contacto, las tensiones pueden disiparse hacia el ápice de la raíz. Las tensiones se disipan mejor en el tejido de soporte del semiarco superior.
\end{abstract}

Palabras clave: Oclusión dental; Sistema estomatognático; Análisis de elementos finitos.

\title{
1. Introdução
}

Os contatos oclusais são considerados fatores importantes a serem considerados diante do tratamento odontológico, pois contatos prematuros oclusais podem implicar em danos potenciais a saúde bucal. (Brandini et al, 2012; Wang \& Yin 2012). O conhecimento desses danos motiva a comunidade científica a realizar estudos para melhor entendimento da distribuição de tensões geradas por diferentes contatos oclusais prematuros e seus efeitos nas estruturas do sistema estomatognático.

Os contatos prematuros podem ocorrer quando a mandíbula se fecha em uma posição fisiológica e é desviada para ocorrer o contato dentário máximo (Miller et al, 2003). Esse desvio ocorre quando as superfícies de contato prematuro deslizam uma sobre a outra e os dentes se movem para a intercuspidação máxima, fazendo com que forças excêntricas sejam transmitidas através do dente para os tecidos de sustentação. A repetição desse movimento causa uma nova atividade reflexa que desvia a mandíbula para uma nova posição, resultando na perda da sua estabilidade funcional (Miller et al, 2003; Reyes et al, 2009).

Forças oclusais excessivas podem causar microfraturas na coroa do elemento dentário e fratura radicular, podendo causar a perda do elemento dentário (Correia et al, 2020). Além disso, rupturas do esmalte dentário podem criar espaços que são preenchidos com moléculas de água, o que impedem a formação de novas conexões químicas, tornando vulneráveis à ação química e às forças físicas geradas por processos fisiológicos ou mecânicos (Lim et al, 2020; Pai et al, 2020). Essa perda adicional da estrutura dentária muitas vezes resulta em lesões de cáries ou lesões cervicais não cariosas (NCCLs), uma das principais causas da sensibilidade dentária (Medeiros et al, 2020; Correia et al, 2020).

Os aspectos dos eventos biomecânicos que resultam de contatos prematuros oclusais sobre os dentes e seus tecidos de suporte, ainda não estão suficientemente esclarecidos. Assim, avaliar os efeitos gerados da distribuição de tensão nos dentes e tecidos de sustentação entre diferentes interferências oclusais podem contribuir para melhor compreendimento. Entretanto, muitas vezes se torna inviável e de difícil entendimento realizar tais análises através de estudos in vivo ou in vitro (Yang et al, 2015). Como alternativa a análise dos elementos finitos pode ser útil para avaliar os resultados sobre as tensões, imitando as condições clínicas (El-Anwar et al, 2015).

Diante disso, o propósito deste estudo foi avaliar, por meio do método de elementos finitos tridimensional, a distribuição das tensões, nos dentes e tecidos de sustentação, geradas por diferentes contatos prematuros em primeiro molar superior e inferior. 


\section{Metodologia}

O estudo foi delineado considerando dois contatos prematuros possíveis de ocorrer clinicamente entre molares, sendo contato prematuro em contato "A" e contato "B" (Cerveira Netto e Zanatta,1998). O contato "A" é estabelecido entre a vertente triturante da cúspide de não-contenção do dente superior (vestibular) com a vertente lisa da cúspide de contenção do dente inferior (vestibular), enquanto o contao "B" é estabelecido entre a vertente triturante da cúspide de contenção do dente superior (palatino) com a vertente triturante da cúspide de contenção do dente inferior (vestibular) (Figura 1).

Figura 1. Localização do contato prematuro. A e B: contato prematuro "A"; C e D: contato prematuro em "B".

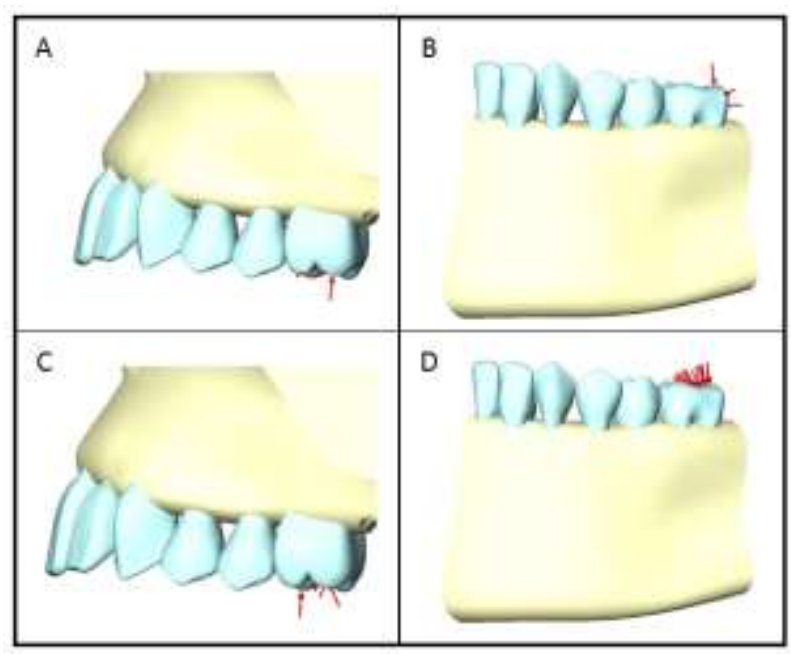

Fonte: Autores.

Os modelos computacionais representando os hemi-arcos foram criados através do software Solidworks®. As malhas foram geradas a reproduzir fidelidade geométrica próximo ao real, sendo do tipo Standard Draft Mesh sólida com cerca de 436.197 nós e 312.485 elementos, cada modelo (Figura 2).

Figura 2. Modelos Computacionais. A: Hemi-arco superior; B: Hemi-arco inferior.

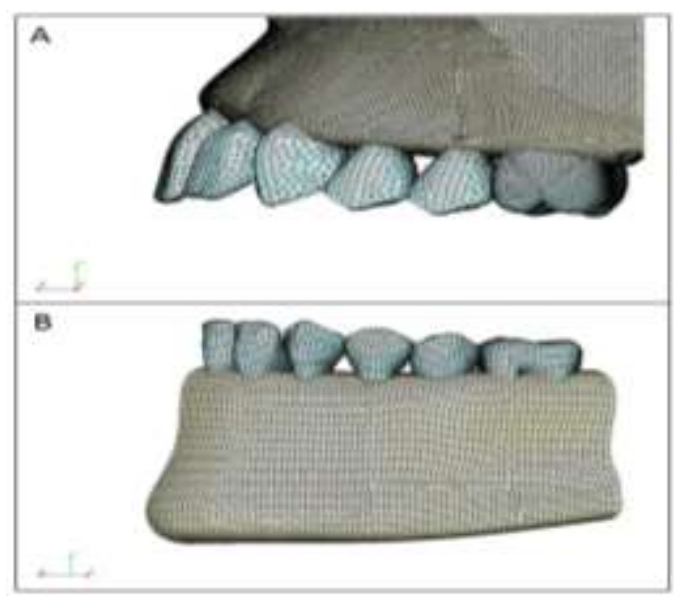

Fonte: Autores.

As geometrias geradas foram exportadas para o software de elementos finitos (Cosmos. Design Star, Structural Research and Analysis Corporation, USA), no qual as propriedades mecânicas de cada estrutura utilizada no estudo foram incorporadas e atribuídos aos valores citados na literatura (Tabela 1). 
Tabela 1. Propriedade dos materiais.

\begin{tabular}{|c|c|c|c|c|}
\hline Estrutura & $\begin{array}{c}\text { Módulo de Elasticidade } \\
(\mathbf{E})(\mathbf{G P a})\end{array}$ & $\begin{array}{c}\text { Coeficiente de } \\
\text { Poisson } \mathbf{( v )}\end{array}$ & $\begin{array}{c}\text { Densidade } \\
\left(\mathbf{g} / \mathbf{c m}^{\mathbf{3}}\right)\end{array}$ & Referência \\
\hline $\begin{array}{c}\text { Dentes e Processo } \\
\text { Alveolar }\end{array}$ & 84,1 & 0,30 & 3,0 & Kohn (2004) \\
\hline $\begin{array}{c}\text { Tecido Ósseo maxila } \\
\text { e mandíbula }\end{array}$ & 18,0 & 0,33 & 0,7 & Kohn (2004) \\
\hline
\end{tabular}

Fonte: Autores.

Os cálculos matemáticos de cargas e tensões foram realizados pelo software Cosmos Design Star (Structural Research and Analysis Corporation, USA). A carga foi aplicada foi de 100 N, simulando os contatos prematuros "A" e "B", conforme Rossi et al (2021). Os modelos de teste foram realisados em uma estação de trabalho HP (Hewlett-Packard Development Company, L.P., Palo Alto, California, USA), com as seguintes características: processador Intel® Xeon® x3470, 16 GB de RAM e 2 TB de HD. Desta forma, os resultados foram transferidos ao software Cosmos Design Star (Structural Research and Analysis Corporation, USA) para o pós-processamento e visualização gráfica das tensões através de mapas. Foi utilizado Mapas de von Mises (TvM) para avaliar o dente e o tecido ósseo em diferentes imagens. A unidade de medida usada para mensurar a Tensão de von Mises foi Mega-Pascal (Mpa), utilizando escala de 0-100 Mpa.

\section{Resultados}

O contato prematuro "A" gerou no primeiro molar superior tensões máximas nas cúspides vestibulares, sendo a tensão dissipada ao longo das raízes vestíbulo-mesial e raiz palatina, atingindo tensão máxima no ápice da raiz vestíbulo-mesial. Enquanto que o contato prematuro "B" gerou no primeiro molar superior tensões máximas nas cúspides palatinas, sendo a tensão dissipada ao longo das raízes vestíbulo-mesial e raiz palatina, mas sem atingir tensões máximas (Figura 3).

Figura 3. Contato prematuro no primeiro molar superior. A: Contato prematuro "A". B: Contato prematuro "B".

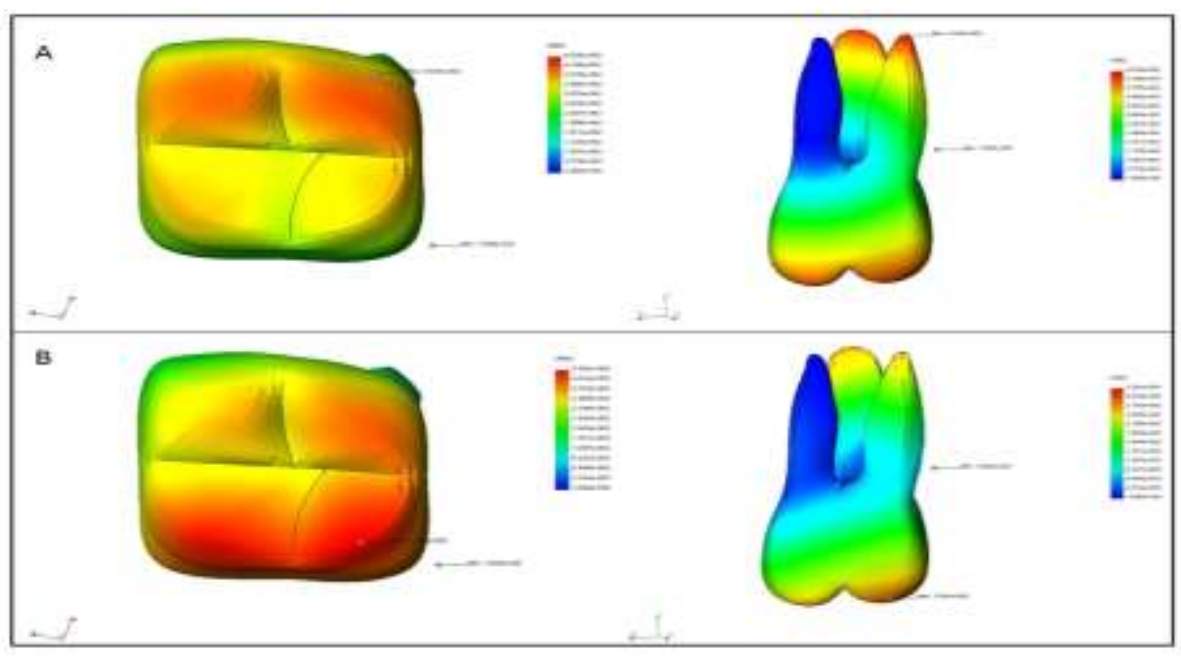

Fonte: Autores.

O contato prematuro "A" gerou no primeiro molar inferior tensões máximas na cúspide vestíbulo-distal, sendo a tensão dissipada e bem distribuída ao longo das raízes mesial e distal. Enquanto que o contato prematuro "B” gerou no 
primeiro molar inferior tensões máximas na cúspide vestíbulo-distal, sendo a tensão dissipada ao longo das raízes mesial e distal, sem atingir tensões máximas (Figura 4).

Figura 4. Contato prematuro no primeiro molar inferior. A: Contato prematuro "A". B: Contato prematuro "B".

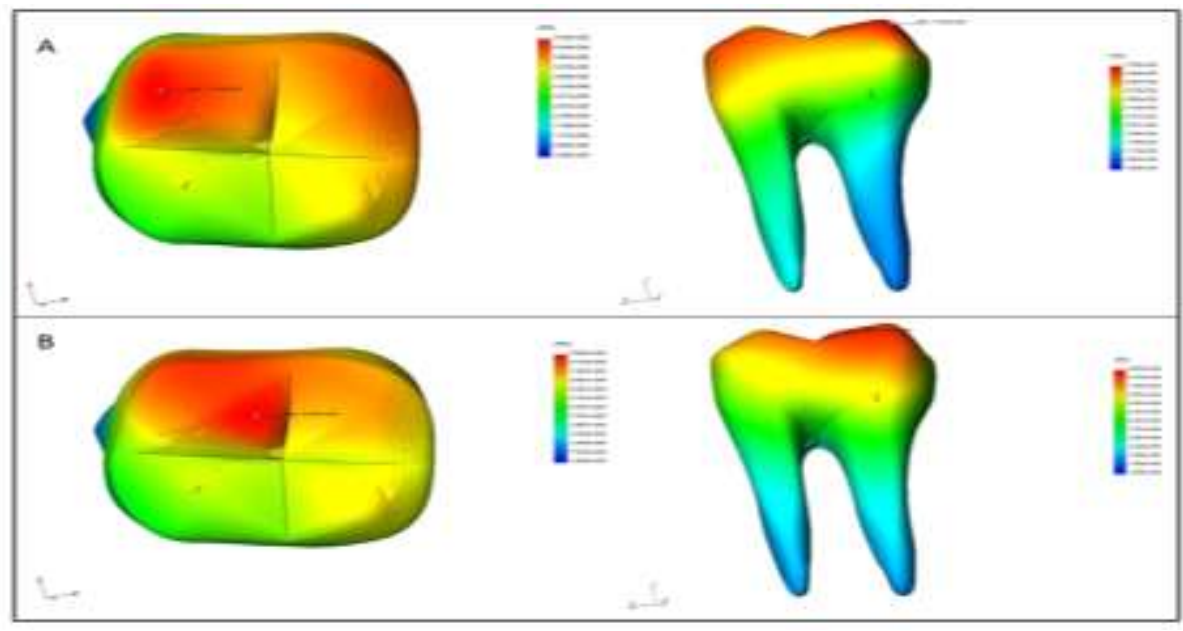

Fonte: Autores.

O contato prematuro "A" gerou pouca tensão no tecido de sustentação superior, sendo encontrado pequenas tensões distribuída em região de furca das raízes vestíbulo-mesial e distal. Enquanto que o contato prematuro "B" também gerou pouca tensão no processo alveolar superior, sendo encontrado pequenas tensões distribuída em região de furca das raízes vestíbulomesial e distal (Figura 5).

Figura 5. Contato prematuro no processo alveolar do primeiro molar superior. A: Contato prematuro "A". B: Contato prematuro "B".

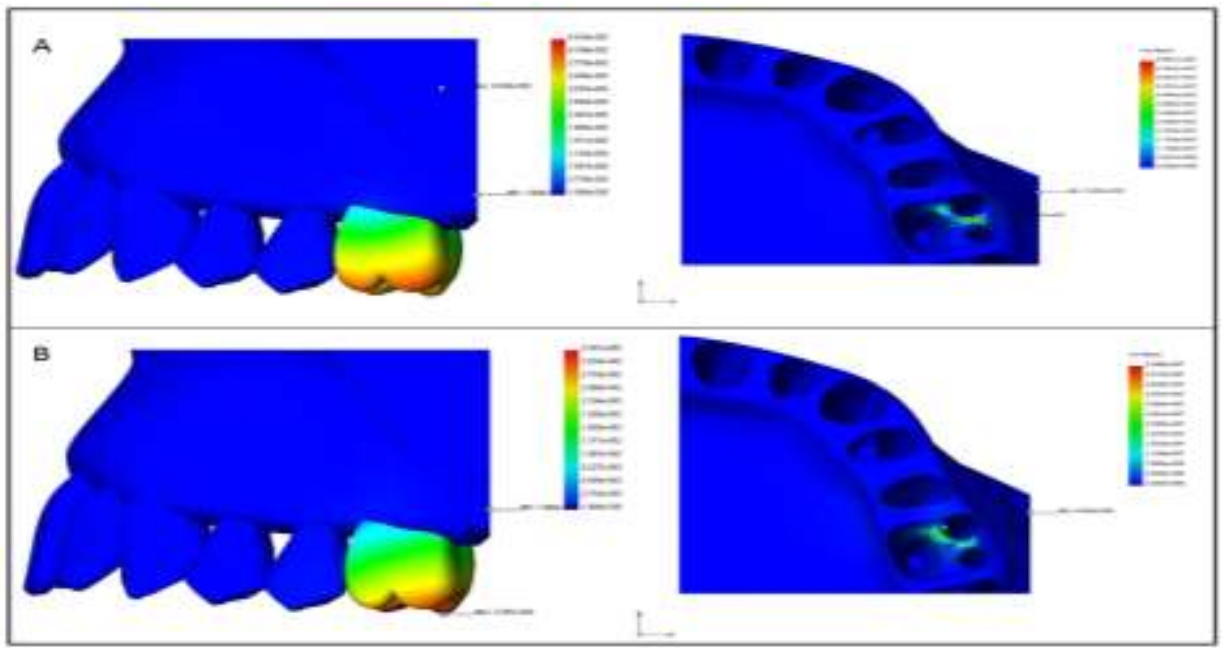

Fonte: Autores.

O contato prematuro "A" gerou tensões no tecido de sustentação inferior, sendo encontrado grande distribuição de tensão na tábua óssea vestibular e pequenas distribuições de tensões nas regiões distal e mesial, mas sem presença de tensões máximas. Enquanto que o contato prematuro "B" também gerou tensões no processo alveolar inferior com distribuição na tábua óssea vestibular e pequenas concentrações foram encontradas na região distal, mas sem presença de tensões máximas (Figura 6). 
Figura 6. Contato prematuro no processo alveolar do primeiro molar inferior. A: Contato prematuro "A". B: Contato prematuro "B".

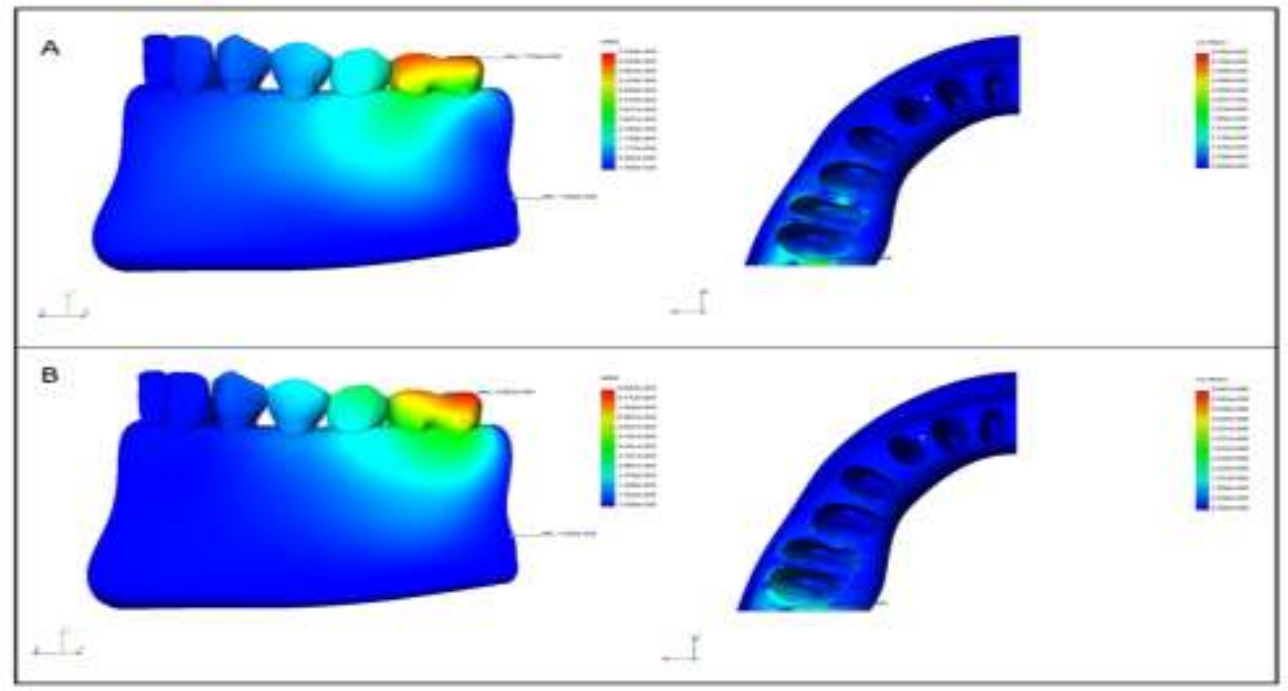

Fonte: Autores.

\section{Discussão}

Os resultados dessa pesquisa realizada pelo método de elementos finitos, reforçam a importância da manutenção da morfologia oclusal, principalmente em procedimentos odontológicos que podem vim a alterar a oclusão, como exemplo a restauração dentária, pois a presença de pontos de contato prematuro pode gerar tensões nas cúspides cêntricas de molares, levando a atingir o ápice da raiz.

O contato prematuro "A" em molares gerou uma tensão que se dissipa pela cúspide vestibular, concentrando-se na coroa do elemento dentário e podendo ser distribuída pela raiz até atingir o ápice, como foi observado no primeiro molar superior. As concentrações de tensões nas cúspides podem gerar fratura do esmalte e, consequentemente, lesões cariosas e sensibilidade, além de perda de função (Dejak et al, 2005). A distribuição de tensão ao longo eixo das raízes podem ser um risco de fratura radicular, o que levaria a perda do elemento dentário, principalmente quando tensões máximas são transferidas ao ápice, como observado no primeiro molar superior em contato prematuro "A" (Rossi et al, 2021).

O contato prematuro "B" em molares gerou tensões menores que o contato prematuro em "A", e a dissipação da tensão fica limitada a coroa clínica, não sendo distribuída ao longo eixo da raiz. Esse resultado é compatível com o estudo de (Correia et al, 2020), segundo os quais, um toque não equilibrado, na superfície oclusal, gera tensão de forma oblíqua, assim tais cargas não seriam tão bem dissipadas, o que levaria mais facilmente ao desgaste das cúspides ou fratura da coroa, sendo este um quadro de melhor reversibilidade que uma fratura radicular.

Em relação aos resultados das tensões geradas no tecido de sustentação o hemi-arco superior apresentou menor concentração de tensões tanto em contato prematuro "A" quanto em "B", possivelmente por ser um osso mais poroso e, consequentemente distribuir melhor as tensões. Entretanto, pequenas tensões foram encontradas na região cervical das raízes vestíbulo-mesial e distal, o que pode gerar um comprometimento de furca, e consequentemente perda do elemento dentário. Em relação ao hemi-arco inferior, grandes tensões foram observadas na tábua óssea vestibular, possivelmente pela mandíbula ser um osso mais denso, assim apresenta menor capacidade de distribuição. Entretanto, pequenas tensões foram encontradas próximo aos terços cervicais das raízes, o que também poderia gerar comprometimento de furca.

Esses achados corroboram com a afirmação de Reyes et al (2009), segundo a qual uma força anormal na superfície oclusal do dente poderá comprometer o periodonto, pois o contato prematuro gera uma força resultante não axial, concentrando 
a tensão na região de inserção do desmodonto, podendo ser um dos fatores a causar doenças periodontais. Como as tábuas ósseas do processo alveolar e a porção radicular do dente são vascularizadas e inervadas, a tensão gerada na região pode causar alteração dessas estruturas, o que justificaria a afirmativa de Medeiros et al, (2020), segundo os quais, um leve contato prematuro pode alterar a percepção do dente e causar dor.

Esse estudo se limita aos fatores secundários presentes em condições clínicas, como saúde bucal, higienização e hábitos parafuncionais, assim se torna necessário que maiores diretrizes de práticas clínicas sejam realizadas para melhor entendimento das possíveis complicações clínicas que contatos prematuros podem gerar, trazendo maior entendimento ao profissional.

\section{Conclusão}

Os pontos de contato prematuro em primeiros molares geraram grandes concentração de tensões nas cúspides cêntricas, sendo que nos primeiros molares superiores, dependendo do tipo de contato, as tensões podem se dissipar para o ápice da raíz. As tensões são melhor dissipadas no tecido de sustentação do hemi-arco superior.

\section{Referências}

Brandini, D. A., Trevisan, C. L., Panzarini, S. R., \& Pedrini, D. (2012). Clinical evaluation of the association between noncarious cervical lesions and occlusal forces. The Journal of prosthetic dentistry, 108(5), 298-303. https://doi.org /10.1016/S0022-3913(12)60180-2.

Cerveira Netto, H.; Zanatta, E. (1998) Manual Simplificado de Enceramento Progressivo. Artes Médicas, p. 1-16.

Correia, A., Bresciani, E., Borges, A. B., Pereira, D. M., Maia, L. C., \& Caneppele, T. (2020). Do Tooth- and Cavity-related Aspects of Noncarious Cervical Lesions Affect the Retention of Resin Composite Restorations in Adults? A Systematic Review and Meta-analysis. Operative dentistry, 45(3), E124-E140. https://doi.org/10.2341/19-091-L

Dejak, B., Mlotkowski, A., \& Romanowicz, M. (2005). Finite element analysis of mechanism of cervical lesion formation in simulated molars during mastication and parafunction. The Journal of prosthetic dentistry, 94(6), 520-529. https://doi.org/10.1016/j.prosdent.2005.10.001

El-Anwar, M. I., Yousief, S. A., Soliman, T. A., Saleh, M. M., \& Omar, W. S. (2015). A finite element study on stress distribution of two different attachment designs under implant supported overdenture. The Saudi dental journal, 27(4), 201-207. https://doi.org/10.1016/j.sdentj.2015.03.001

Lanza, A., Aversa, R., Rengo, S., Apicella, D., \& Apicella, A. (2005). 3D FEA of cemented steel, glass and carbon posts in a maxillary incisor. Dental materials: official publication of the Academy of Dental Materials, 21(8), 709-715. https://doi.org/10.1016/j.dental.2004.09.010

Lim, G. E., Son, S. A., Hur, B., \& Park, J. K. (2020). Evaluation of the relationship between non-caries cervical lesions and the tooth and periodontal tissue: An ex-vivo study using micro-computed tomography. PloS one, 15(10), e0240979. https://doi.org/10.1371/journal.pone.0240979

Medeiros, T., Mutran, S., Espinosa, D. G., do Carmo Freitas Faial, K., Pinheiro, H., \& D'Almeida Couto, R. S. (2020). Prevalence and risk indicators of noncarious cervical lesions in male footballers. BMC oral health, 20(1), 215. https://doi.org/10.1186/s12903-020-01200-9

Miller, N., Penaud, J., Ambrosini, P., Bisson-Boutelliez, C., \& Briançon, S. (2003). Analysis of etiologic factors and periodontal conditions involved with 309 abfractions. Journal of clinical periodontology, 30(9), 828-832. https://doi.org/10.1034/j.1600-051x.2003.00378.x

Pai, S., Bhat, V., Patil, V., Naik, N., Awasthi, S., \& Nayak, N. (2020). Numerical Three-dimensional Finite Element Modeling of Cavity Shape and Optimal Material Selection by Analysis of Stress Distribution on Class V Cavities of Mandibular Premolars. Journal of International Society of Preventive \& Community Dentistry, 10(3), 279-285. https://doi.org/10.4103/jispcd.JISPCD_75_20

Reyes, E., Hildebolt, C., Langenwalter, E., \& Miley, D. (2009). Abfractions and attachment loss in teeth with premature contacts in centric relation: clinical observations. Journal of periodontology, 80(12), 1955-1962. https://doi.org/10.1902/jop.2009.090149

Rossi, A. C., Freire, A. R., Ferreira, B. C., Faverani, L. P., Okamoto, R., \& Prado, F. B. (2021). Effects of premature contact in maxillary alveolar bone in rats: relationship between experimental analyses and a micro scale FEA computational simulation study. Clinical oral investigations, 25(9), 5479-5492. https://doi.org/10.1007/s00784-021-03856-1

Silva, N. R., Castro, C. G., Santos-Filho, P. C., Silva, G. R., Campos, R. E., Soares, P. V., \& Soares, C. J. (2009). Influence of different post design and composition on stress distribution in maxillary central incisor: Finite element analysis. Indian journal of dental research: official publication of Indian Society for Dental Research, 20(2), 153-158. https://doi.org/10.4103/0970-9290.52888

Wang, C., \& Yin, X. (2012). Occlusal risk factors associated with temporomandibular disorders in young adults with normal occlusions. Oral surgery, oral medicine, oral pathology and oral radiology, 114(4), 419-423. https://doi.org/10.1016/j.oooo.2011.10.039

Yan, X., Zhang, X., Chi, W., Ai, H., \& Wu, L. (2015). Comparing the influence of crestal cortical bone and sinus floor cortical bone in posterior maxilla bicortical dental implantation: a three-dimensional finite element analysis. Acta odontologica Scandinavica, 73(4), 312-320. https://doi.org/10.3109/00016357.2014.967718 